\title{
Mitologias e a nova crítica da ideologia na França
}

\author{
Gabriel Ferreira Zacarias
}

RESUMO: Neste artigo, retomo a noção de mitologia, formulada por Roland Barthes em seu livro de 1957. Barthes procura compreender a especificidade da ideologia veiculada pelos produtos da indústria cultural a partir de seu funcionamento linguístico, caracterizado pelo autor como uma operação de apropriação discursiva, ou de "roubo da linguagem". Em seguida, aproximo o conceito barthesiano do procedimento artístico formulado por Guy Debord sob o nome de détournement (ou desvio). Empregado por Debord em seus textos e filmes, tal procedimento é concebido como uma forma de reapropriação e ressignificação dos produtos da cultura de massas que busca reverter seu conteúdo ideológico habitual. Pode-se propor, portanto, que o desvio de Debordrealiza na prática aquilo que Barthes imaginara teoricamente com a noção de "mito artificial". PALAVRAS-CHAVE: Mitologia; Détournement; Desvio; Ideologia; Indústria cultural; Sociedade do espetáculo.

\section{Mythologies and the new critique of ideology in France}

ABSTRACT: In the following article I depart firstly from the concept of mythology, as presented by Roland Barthes in his work in 1957, where he tries to grasp the specificity of ideology in mass culture. The myth is characterized by Barthes as a form of discursive appropriation, or even as a "theft of language". Secondly, I draw a parallel between the barthesian concept of myth and the artistic procedure formulated by Cuy Debord under the name of détournement. Such a procedure, employed by Debord in his texts and cinematographic works, wasconceived as a way of re-appropriating and re-signifying the products of cultural industry, having as an ultimate goal to neutralize and reverse its ideological content. In that sense, Debord's détournement can be seen as a practical realization of Barthes' theoretical idea of "artificial myth".

KEYWORDS: Mythology; Détournement; Shift; Ideology; Cultural industry; Society of the spectacle.

Ao escrever Mitologias, Roland Barthes não pretendia simplesmente catalogar os "mitos de hoje" - como sugere, por exemplo, a tradução italiana da obra. Seu objetivo não era de reificar a função "mítica" dos produtos da nova cultura de massas, mas sim, como entusiasta de Brecht que era, de produzir um "efeito de distanciamento" com relação a esses mitos. Em outras palavras, o livro de Barthes foi concebido como uma tentativa de renovação da crítica da ideologia, como revela o autor no seu prefácio de 1970 . Distante da ortodoxia marxista, Barthes pode dar atenção àquilo que o marxismo oficial, dominado por um viés economicista, desdenhava como simples "superestrutura". Ele tentara assim um ousado cruzamento entre Marx e Saussure, analisando os produtos culturais como veiculadores de significação, uma significação, ademais, dupla, pois o específico do "mito" seria justamente sua capacidade de ressignificação dos signos já existentes. Mitologias é, desta forma, um livro plenamente inserido no contexto de sua época. Sensível à explosão da indústria cultural no pós-segunda-guerra, influenciado, por um lado, pelo debate marxista (e suas carências) que domina a crítica de esquerda, e, por outro lado, pela linguística de Saussure que aparece como base do estruturalismo em ascensão nos meios acadêmicos franceses - movimento ao qual a obra de Barthes contribui consideravelmente. Mas Mitologias deve ser também colocado em relação com uma das principais vertentes da nova arte de vanguarda que tem por característica a reapropriação de elementos da indústria cultural. Revertendo o gesto disruptivo do ready-made de Duchamp em procedimento construtivo de uma nova arte, muitos artistas fizeram da incorporação de materiais já existentes uma forma de produção artística propícia à reflexão crítica sobre a modernidade capitalista. A "publicidade em profundidade" que Barthes encontrara nos reclames de saponáceos e detergentes parece ecoar em obras como o Brillo Box (1964) de Warhol e aHigiene da visão (1960) de Martial Raysse. Mais importante, ressoa também na obra de Guy

\footnotetext{
1 Pós-doutorando em Sociologia pela Universidade de São Paulo, com bolsa da FAPESP. Doutor em Estudos Culturais pela Universidade de Perpignan (França) e pela Universidade Bergamo (Italia), com estágio doutoral na Universidade de Paris 10 (França).E-mail para contato: gabrielzacarias@gmail.com.
} 
Debord, como em seu livro de artista Mémoires (1959) - onde encontramos o slogan da propaganda de OM0, do qual fala Barthes - ou em seu filme sur le passage de quelques personnes à travers une assez courte unité de temps (1959) - onde encontramos a publicidade da marca Monsavon, estrelada pela futura starlette de Codard, Anna Karina, que parece encarnar o "prazer espumoso" do sabonete. A noção situacionista de détournement (desvio), formulada por Guy Debord, busca dar conta justamente dessa forma de criação artística que, como veremos, pode bem ser aproximada da noção barthesiana de "mito artificial", notadamente em seu funcionamento linguístico.

Antes de tudo, cumpre lembrar que, publicado em 1957, Mitologias, de Roland Barthes, reúne uma série de pequenos textos que o autor escrevera nos três anos precedentes. Servindo-se do aporte teórico trazido pela linguística de Saussure, Barthes propunha-se a desvendar as significações produzidas pelos conteúdos veiculados na cultura de massas. 0 livro de Barthes é, assim, uma das obras fundadoras da semiologia, que viveria seu apogeu na década seguinte. Mas o livro de Barthes não se propunha inicialmente a fundar uma disciplina. Estava mais próximo de uma obra de crítica da ideologia, no sentido inaugurado um século antes por Marx e Engels com A Ideologia alemã. Em uma época em que o marxismo ortodoxo prestava pouquíssima atenção aos fenômenos culturais, descreditados como meros epifenômenos "superestruturais", coube então a Barthes, autor sem vínculos políticos, desvendar o modo de funcionamento semiológico da ideologia burguesa na era da comunicação de massas.

Além de reunir os pequenos textos que escrevera em sua coluna "Pequenas mitologias" (Petites mythologies), na revista Lettres Nouvelles, o livro trazia ainda uma segunda parte, intitulada 0 Mito hoje, em que Barthes apresentava de maneira mais clara seus conceitos de "mito" e "mitologia", elaborando o modo de funcionamento linguístico do mito. Não se tratava então, simplesmente, de reconhecer, como se faz habitualmente e de maneira aproblemática, que os mitos modernos passaram a ser produzidos pela indústria cultural, dada a amplidão do impacto de seus produtos. Nessa acepção, as estrelas de cinema seriam como a versão contemporânea do olimpo. Longe disso, com a noção de "mitologia", Barthes propunha na verdade a fundação de uma ciência crítica do "mito". E o mito era para ele, antes de tudo, o modo de produção de sentido operante na nova ideologia. 0 mito não estava nos conteúdos, mas na forma de significação desses conteúdos. Em suma, o mito, para Barthes, é uma forma, e não um conteúdo. Daí a variedade dos conteúdos analisados pelo autor em seu livro, difíceis de enquadrar em uma tipologia precisa: o cérebro de Einstein, o rosto de Greta Garbo, o strip-tease ou a nova Citroën DS, todos são tratados como "objetos míticos".

Como é definido então o mito? "0 mito é uma fala (parole)", escreve Barthes, "um sistema de comunicação, uma mensagem" (BARTHES, 1957, p. 181). Isto significa que quando Barthes emprega a palavra "mito" ele pensa em uma forma específica de uso da linguagem, ou ainda em uma forma específica de transformação dos objetos em linguagem. 0 que permanece, portanto, é o modo de significação: "0 mito não se define pelo objeto de sua mensagem, mas pela forma com a qual a profere: existem limites formais ao mito, mas não substanciais". (BARTHES, 1957, p. 181). A conclusão que Barthes obtém a partir desta definição do mito como forma é que "posto que o mito é uma fala (parole), tudo que é passível de discurso pode ser mito". (BARTHES, 1957, p. 181). Se lembrarmos que para Barthes é discurso "toda unidade ou síntese significativa, quer verbal ou visual" (BARTHES, 1957, p. 183), isto quer dizer que não são apenas as palavras, mas também as imagens que podem se ver presas do "mito". A especificidade do mito enquanto modo de significação é "que ele se edifica a partir de uma cadeia semiológica que existe antes dele: ele é um sistema semiológico segundo" (BARTHES, 1957, p. 187). Em outros termos, o mito é uma forma de produção de sentido que passa necessariamente pela apropriação de um discurso preexistente. Ele é, como diz Barthes, um "roubo de linguagem". Se pensarmos no esquema de Saussure, isto quer dizer que "o que é signo (isto é, total associativo de um conceito e de 
uma imagem) no primeiro sistema, se torna significante no segundo" (BARTHES, 1957, p.187). Barthes nos apresenta, portanto, o seguinte esquema para apreender as relações significantes entre os dois sistemas semiológicos:

LÍNGUA

1. Significante 2.Significado

3. Signo [Sentido]

I. SIGNIFICANTE [Forma] II. SIGNIFICADO [Conceito]

\section{SIGNO [Significação]}

Barthes mostra aqui que há dois sistemas semiológicos operando no interior do mito. 0 primeiro sistema é o da língua, ou os modos de representação que lhe são assimilados. Trata-se, em todo caso, de uma linguagem-objeto, que remete à representação do mundo. 0 mito, inversamente, não remete mais ao mundo, pois parte de uma representação já existente. Ele é, portanto, uma metalinguagem, "porque ele é uma segunda língua, na qual fala-se da primeira" (BARTHES, 1957, p. 188). Daí que Barthes sustenta uma abordagem comum à escrita e à imagem, aplicando igualmente à segunda o esquema de compreensão de Saussure, e abrindo o caminho para a semiótica. Pois, como nota o autor, tanto a linguagem verbal quanto a visual são compostas de signos e constituem ambas uma linguagem-objeto. Assim sendo, ambas estão também no "umbral do mito", podendo ser apropriadas por este na constituição de uma segunda cadeia de significados.

Barthes dá uma importância fundamental a essa passagem entre os dois sistemas. 0 mito constitui um processo de formalização, esvaziando o significado anterior do signo que é apropriado. Esvaziado, porém, esse significado não é inteiramente abolido. Pelo contrário, como nota Barthes, "o significado perde seu valor, mas conserva a vida, da qual a forma do mito se alimenta" (BARTHES, 1957, p. 191). 0 espaço aberto pelo esvaziamento do mito será preenchido por uma nova significação, a qual Barthes chama de "conceito". 0 conceito nem suprime nem esconde o significado original, na verdade, ele o deforma. Tomemos um dos exemplos do autor para que essa operação se torne mais palpável. Barthes nos fala de uma fotografia encontrada em uma capa de revista, na qual um soldado negro de uma colônia africana saúda a bandeira francesa. A fotografia não transmite nenhum conteúdo sobre 0 soldado que nela é retratado. Sua biografia está desde início "colocada entre parênteses para que se libere a imagem". 0 valor de linguagem-objeto da imagem é ínfimo e ela se presta logo à deformação do conceito. 0 conceito que recobre a imagem é o do caráter imperial da França (impérialité française), a significação mítica que ela produz é a de uma natureza imperial do povo francês. Percebemos como esse conceito é "instável" e historicamente determinado, tendo hoje perdido todo seu sentido. Mas, se por um lado, o conceito só funciona dentro de um contexto significativo historicamente determinado, que permite sua decodificação, sua função ideológica é justamente de ocultar a história. Segundo Barthes, o traço maior da ideologia burguesa é de ocultar o caráter eminentemente histórico da sociedade moderna, naturalizando o mundo social. A operação de formalização do mito, que esvazia o sentido original dos signos, corresponderia linguisticamente a essa ocultação. No exemplo citado, o gesto triunfal da saudação da bandeira naturaliza o processo histórico 
da colonização, e a harmonia da imagem oculta a violência da imposição da cultura francesa. É como se a França houvesse sempre sido um Império, e como se os africanos houvessem sempre sido seus colonos. Barthes conclui, portanto, que "o mito opera a inversão da antiphysis em pseudo-physis" (BARTHES, 1957, p. 216), seu "princípio mesmo" é o de "transformar a história em natureza". (BARTHES, 1957, p. 202)

Mas se o mito furta a linguagem, se tudo que é discurso pode se tornar presa do mito, como podemos escapar ao mito? Barthes propõe que a melhor maneira de combater o mito pode ser, justamente, mitificá-lo. Isto é, construir uma nova cadeia de significados a partir do furto dos signos mitificados. Ora, aquilo que Barthes imagina aqui teoricamente parece muito próximo da prática do desvio empregada por Guy Debord em suas obras, sobretudo em seus filmes. 0 mesmo esquema desenhado por Barthes parece se aplicar bem ao modo de funcionamento daquilo que Debord chamara de desvio (ou détournement).

0 conceito de détournement (desvio), formulado originalmente por Guy Debord, é apresentado de maneira mais sistemática no texto "Manual de instruções do desvio" [Mode d'emploi du détournement, sem tradução no Brasil], escrito em 1956 em parceria com Gil Joseph Wolman (DEBORD, 2006, p. 221-229). 0 desvio ali era proposto como uma nova forma de criação artística assente na reapropriação e ressignificação dos conteúdos culturais. Os autores tomavam como ponto de partida a lição da poesia moderna cujas "descobertas (...) sobre a estrutura analógica da imagem demonstram que entre dois elementos, de origens tão estranhas quanto possível, uma relação sempre se estabelece" (DEBORD, 2006, p.222). Razão pela qual concluíam que "todos os elementos, tomados de qualquer lugar, podem ser objeto de novas aproximações" (DEBORD, 2006, p. 222). Isto os levava a propor que "a apresentação (mise en présence) de duas expressões independentes, superam seus elementos primitivos para dar uma organização sintética de eficácia superior" (DEBORD, 2006, p. 222). Os autores do texto sustentavam, em suma, uma estética baseada na reapropriação de elementos semânticos que deveriam ser recombinados para compor um novo contexto significativo. Em sua forma básica, a simples aproximação de dois elementos estranhos era já suficiente para produzir um novo contexto significativo. E se, como nota Genette, a abertura da imagem clama frequentemente por um comentário verbal que possa confirmar ou atualizar suas significações visuais flutuantes, dispositivo explorado com frequência na imprensa e na publicidade (GENETTE, 1966, p. 190), também na prática do détournement se explorará amiúde a relação entre imagens e textos desviados. Assim, na colagem "Le temps passe, em effet, et nous passons avec lui" (1954), de Guy Debord, que esse evoca como exemplo de desvio em seu texto, ouso do reclame de uma marca de batons, que afirmava que "os belos lábios tem/usam vermelho" (les jolies lèvres ont du rouge), associado a fotografias da guerra civil espanhola, adquire um novo sentido, abertamente político. De maneira análoga, encontraremos frequentemente na revista situacionista a combinação entre imagens jornalísticas e citações. Em um desses exemplos encontramos justamente uma citação de Roland Barthes, extraída do Grau zero da escrita, que trata da escrita como âmbito da escolha política do escritor que articula a liberdade à memória. A fotografia retrata um carro grafitado com escritas de apoio à independência argelina. A legenda dada à foto, "A Argélia e a escritura", faz a ligação entre o valor memorial e o uso político da escritura empregada aqui como propaganda na luta pela descolonização.

os exemplos mencionados revelam a força política do desvio. Com efeito, ao formular a ideia do desvio, Debord e Wolman não tinham por ambição renovar as práticas de produção artística. Pelo contrário, opostos que eram à especialização da arte, compreendiam o desvio como um instrumento poderoso no embate político-ideológico de seu tempo. Na abertura de seu texto, os autores afirmavam acreditar que "todos os meios de expressão conhecidos vão confluir em um movimento geral de propaganda que deve abraçar todos os aspectos, em perpétua interação, da realidade social." (DEBORD, 2006, p. 221) Por essa razão, propunham que "a herança literária e artística da humanidade [fosse] utilizada para fins de propaganda engajada". (DEBORD, 2006, p. 221) 
A prática do desvio continuará central na obra de Guy Debord, mesmo na redação de $A$ sociedade do espetáculo (1967). Mas é sobretudo em seus filmes que sua relação com a noção de mitologia se torna mais evidente. Ali, Debord se apropria de imagens publicitárias e as ressignifica em sentido diverso, com valor por vezes lírico, e no mais das vezes político. Não à toa, em $A$ sociedade do espetáculo Debord afirmará ainda que "o desvio é a linguagem fluída da anti-ideologia" (DEBORD, 1967, p. 208) Assim, o desvio opera uma verdadeira mitologia prática, isto é, uma crítica da ideologia realizada através da ressignificação dos conteúdos veiculados pela cultura de massas.

Um bom exemplo dessa operação encontramos em uma sequência do curta-metragem Réfutation de tous les jugements, tant élogieux qu'hostiles, qui ont été jusqu'ici portés sur le film « La Société du Spectacle » (1975), na qual Debord se apropria de uma propaganda de Iced Tea. A propaganda representa o Sul do Estados Unidos às vésperas da Guerra de Secessão. 0 sul escravista é representado de maneira idílica até ser destruído pela violência das tropas do Norte. 0 advento da Guerra, e a derrota das tropas sulistas, decretam o fim dessa "civilização". Ao que se segue o slogan "sua civilização desapareceu, tudo o que restou foi o chá gelado". A propaganda é sem dúvida interessante. A civilização que acabou não é outra que a civilização escravista. Claro, não há na publicidade nenhuma menção direta ao escravismo sulista. Mas o núcleo do caráter ideológico não está nessa idealização da sociedade escravista. Afinal, reconhece-se que esta situação é um passado acabado ao qual não se pode retornar. 0 caráter ideológico está aqui naquilo que já apontava claramente Roland Barthes: a reversão da história em natureza, ali mesmo onde o movimento histórico aparece como fundamento da sociedade burguesa. Ora, o que decreta o fim da sociedade escravista não é outra coisa que o advento do capitalismo, o qual necessita de relações livres de trabalho. Mas ao invés de evidenciar o caráter eminentemente histórico da sociedade capitalista, que acarreta justamente na transformação constante das relações de produção, a publicidade busca sustentar que, apesar de todas essas mudanças, algo continua igual. 0 chá gelado sobreviveu, ele ainda é o mesmo. Em outras palavras, se há algo que continua imutável em meio a todos os grandes câmbios históricos, esse algo é a mercadoria. Eis a mentira favorita da ideologia veiculada pela publicidade, a principal naturalização almejada pelo mito: fazer crer que os produtos criados pelo homem sempre foram mercadorias. Fazer esquecer que a mercadoria é, como o mito, uma forma e não um conteúdo. A forma da mercadoria, destrinchada por Marx ao início do Capital, é o que faz a especificidade histórica da produção material do capitalismo, quando os objetos não são mais produzidos em vistas à satisfação humana, mas sim visando à acumulação do valor. 0 objetivo do mito é fazer esquecer essa especificidade e identificar assim forma e conteúdo, como se todo produto humano fosse, necessariamente, mercadoria. Ao se apropriar dessa publicidade, Debord corrige esse anacronismo, revertendo o mito em seu contrário. Superpondo em voz off um discurso crítico ao capitalismo, e deixando emergir ao fim, de maneira isolada, seu slogan final - "sua civilização desapareceu, tudo o que restou foi o chá gelado" - Debord reverte a naturalização do mito e faz com que o "fim da civilização" não se aplique mais à falsa e idealizada sociedade escravista do sul dos EUA, mas sim a verdadeira sociedade produtora de Iced Tea, a sociedade capitalista que lhe é contemporânea. De mito naturalizante da mercadoria, a publicidade é assim revertida em mito do fim do capitalismo. 


\section{REFERÊNCIAS}

BARTHES, Roland. Mythologies, Paris : Editions du Seuil, 1957.

DEBORD, Guy. Mémoires, Copenhague: Permild đa Rosengreen, 1959. . La Société du spectacle, Paris : Buchêt Chastel, 1967. . Euvres, Paris : Gallimard, coll. «Quarto », 2006, pp.221-229

1956. .WOLMAN, Gil J.«Mode d'emploi du détournement » in :.Les Lèvres Nues, n.8 Mai,

GENETTE, Gérard.Figures I, Paris : Editions du Seuil, 1966.

Internationale Situationniste $n^{\circ} 8$, Janvier 1963.

\section{FILMOGRAFIA}

DEBORD, Guy. Sur le passage de quelques personnes à travers une assez courte unité de temps, $\mathrm{p} / \mathrm{b}, 35 \mathrm{~mm}, 20^{\prime}, 1959$.

DEBORD, Guy. Réfutation de tous les jugements, tant élogieux qu'hostiles, qui ont été jusqu'ici portés sur le film «La Société du Spectacle », p/b, 35mm, 20', 1975. 